\title{
Management and clinical outcome of stable coronary artery disease in Austria
}

\author{
Results from 5 years of the CLARIFY registry
}

\author{
Irene M. Lang · Roza Badr-Eslam · Nicola Greenlaw · Robin Young · Philippe Gabriel Steg
}

Received: 23 April 2017 / Accepted: 30 July 2017 / Published online: 14 September 2017

(C) The Author(s) 2017. This article is an open access publication.

\begin{abstract}
Summary
Background The population of patients with established coronary artery disease (CAD) is growing because of an improvement in outcomes and survival from acute disease episodes. Nevertheless, these patients remain at high risk of cardiovascular events. Thus, CAD management is important in prevention of disease progression. The objective of this analysis was to describe disease management and clinical outcome of Austrian outpatients with stable CAD over 5 years by using data from the international CLARIFY registry.

Methods CLARIFY was an international prospective observational registry of outpatients with stable CAD, defined as prior myocardial infarction or revascularization (CABG or PCI), coronary stenosis of more than $50 \%$ by coronary angiography or chest pain with myocardial ischemia. We analyzed demographic characteristics, risk factors, treatments and clinical outcomes of 424 Austrian outpatients with established CAD who
\end{abstract}

Trial registration. Controlled-Trials.com ISRCTN43070564 I.M. Lang, R. Badr-Eslam, N. Greenlaw, R. Young, and P.G. Steg are CLARIFY investigators.

I. M. Lang $(\bowtie) \cdot$ R. Badr-Eslam

Department of Cardiology, AKH-Vienna, Medical University of Vienna, Vienna, Austria

irene.lang@meduniwien.ac.at

N. Greenlaw $\cdot$ R. Young

Robertson Center of Biostatistics, University of Glasgow, Glasgow, UK

\section{P. G. Steg}

Département Hospitalo-Universitaire FIRE, Hôpital Bichat, Assistance Publique - Hôpitaux de Paris, Paris, France

NHLI Imperial College, ICMS, Royal Brompton Hospital, London, UK were enrolled between November 2009 and July 2010 and observed until September 2015.

Results The primary risk factors in Austrian outpatients with stable CAD were smoking (current smokers: $13.2 \%)$, overweight $(77.1 \%)$, hypertension (78.5\%), raised low-density lipoprotein (LDL) cholesterol plasma levels $(81.4 \% \geq 0.7 \mathrm{~g} / \mathrm{l}$ or $1.8 \mathrm{mmol} / \mathrm{l})$, elevated heart rate $(\geq 70 \mathrm{bpm}$ : $60.9 \%$ in patients with anginal symptoms) and poor physical activity (none or light activity: 63.4\%). Patients received lipid-lowering drugs (predominantly statins), aspirin, beta-blockers and angiotensin-converting enzyme (ACE) inhibitors according to current recommendations. After 5 years a systolic blood pressure (SBP) < $140 \mathrm{mmHg}$ and diastolic blood pressure (DBP) < $90 \mathrm{~mm} \mathrm{Hg}$ was reached in $58.5 \%$ of patients. Of the patients $70.4 \%$ had LDL cholesterol plasma levels below $1.0 \mathrm{~g} / \mathrm{l}(2.6 \mathrm{mmol} / \mathrm{l}), 42.1 \%$ of smokers had stopped smoking, $42.9 \%$ of patients with anginal symptoms had a heart rate $\leq 60 \mathrm{bpm}$ and $26.0 \%$ of diabetic patients had brought their HbAlc levels below 6.5\%. Cardiovascular death, myocardial infarction or stroke occurred in 30 patients $(7.1 \%)$, all-cause death in 25 cases $(5.9 \%)$ and cardiovascular death in 15 cases $(3.5 \%)$. Myocardial infarction was reported in 14 patients (fatal and non-fatal: $3.3 \%$ ) and stroke in 8 patients (fatal and non-fatal: 1.9\%), 39 patients $(9.2 \%)$ underwent myocardial revascularization and 124 patients $(29.2 \%)$ experienced cardiovascular hospitalization.

Conclusion Characteristics of Austrian outpatients with stable CAD corresponded to those of patients with CAD in other developed countries. Medical treatments following the recommendations of the European guidelines were prescribed in the majority of patients; however, recommended goals of life style interventions including a heart rate less than $60 \mathrm{bpm}$ and general risk factor management were not 
achieved by a high proportion of patients. Heart rate control and life style changes remain unmet needs of cardiovascular care in Austria.

Keywords Coronary artery disease - CLARIFY · Treatment $\cdot$ Clinical outcome $\cdot$ Austria

\section{Introduction}

Approximately 17.5 million people die each year from cardiovascular disease. An estimated $30 \%$ of all deaths worldwide are due to heart attacks and strokes. Coronary artery disease (CAD) accounts for the greatest proportion of cardiovascular diseases. Overall, CAD is the leading cause of death worldwide and is predicted to remain so for the next 20 years [1-3]. In Europe between $14 \%$ and $20 \%$ of women and $16-25 \%$ of men die from CAD [4]. Furthermore, CAD is a leading cause of morbidity and poor quality of life. Thus, CAD is a major public health problem which exerts heavy economic costs. Overall, CAD is estimated to have cost the European Union $€ 45$ billion in 2003 and this estimate even might be an underestimate [5]. Nevertheless, improved management of the disease consisting of life style interventions, revascularization or optimal drug therapy have resulted in a decrease in CAD mortality since 1995 by 34\% [6, 7]; however, most data regarding CAD are from patients with acute coronary symptoms or in the case of patients with stable $\mathrm{CAD}$ come from randomized trials of drugs used in the prevention of cardiovascular events (e.g. EUROPA [8]). In order to generalize the findings from these trials, real-life aspects regarding demography and disease management of outpatients with stable CAD are needed. Because of the improvement in outcomes and survival from episodes of acute disease, the population of patients with established CAD is growing. All these patients remain at high risk of cardiovascular events and therefore disease management is important in prevention of disease progression [9, 10].

The prospeCtive observational LongitudinAl RegIstry oF patients with stable coronary arterY disease (CLARIFY) registry was initiated to improve knowledge regarding patients with stable CAD. The registry was designed to collect data on the current status of outpatients with stable $\mathrm{CAD}$, including demography, clinical profiles, therapeutic strategies and clinical outcomes. In this context, the registry includes symptomatic and asymptomatic patients. The main objectives were to define contemporary patients with stable CAD, to identify discrepancies between evidence-based recommendations and practice, and to investigate long-term prognostic determinants [10, $11]$.

This analysis describes disease management and clinical outcomes of Austrian outpatients with stable CAD over 5 years of CLARIFY. Success in disease management and treatment were evaluated by analysis of patients who achieved the following treatment targets: normalized blood pressure, lowered low-density lipoprotein (LDL) cholesterol levels, heart rate $\leq 60 \mathrm{bpm}$ in patients with angina, smoking cessation, and lowered glycated hemoglobin (HbAlc) levels in diabetic patients. In addition, the analysis included a comparison of heart rate and usage of heart ratemodulating medications of Austrian CAD patients with European CAD patients.

\section{Materials and methods}

\section{Study design and patients}

CLARIFY was an international, prospective, observational, longitudinal registry in stable CAD outpatients with 5 years of follow-up. The study rationale, design and methods were described previously [10, 12]. Overall, patients were enrolled in 45 countries worldwide. They were treated according to usual clinical practice at each institution, with no specific tests or therapies defined in the study protocol.

Patients were enrolled when they met at least one of the following inclusion criteria: documented myocardial infarction (more than 3 months ago), coronary stenosis of more than $50 \%$ proven by coronary angiography, chest pain with myocardial ischemia proven by stress electrocardiogram, stress echocardiography or myocardial imaging, and coronary artery bypass grafting (CABG) surgery or percutaneous coronary intervention (PCI) more than 3 months ago. Patients were excluded in cases of hospitalization for cardiovascular disease within the past 3 months (including revascularization) and planned revascularization as well as patients with conditions expected to hamper participation or the 5-year follow-up, such as limited cooperation, limited legal capacity, serious non-cardiovascular disease or conditions interfering with life expectancy (e. g. cancer, drug abuse) or severe cardiovascular disease (e.g. advanced heart failure, severe valve disease, history of valve repair and/or valve replacement).

To ensure that the study population was representative of a real-life population of stable CAD outpatients in each country, recruitment was based on a predefined selection of physician types (cardiologists, internists, primary care physicians) and aimed for consecutive enrolment of eligible patients. Each physician recruited a maximum of 15 outpatients with stable $\mathrm{CAD}$ as defined by the inclusion criteria, the general target enrolment for any participating country was 25 patients per million inhabitants (range 12.5-50). The first patient was included on 26 November 2009 and recruitment was completed on 30 June 2010. The registry ended in September 2015. A total of 424 Austrian patients were included in the registry, $28.1 \%$ of patients were lost to follow-up after 5 years. The study was registered in the ISRCTN registry of clinical trials (ISRCTN43070564). 


\section{Data collection and data management}

Investigators completed electronic case report forms (eCRFs) at baseline and at patient visits 1 year, 2 years, 3 years, 4 years and 5 years after enrolment ( \pm 3 months). Data collected at baseline included demographics, risk factors and life style, medical history and current symptoms, physical examination including heart rate determined by pulse palpation and the results of the most recent electrocardiogram (ECG) performed within the past 6 months, laboratory values (if available: fasting blood glucose, HbAlc, cholesterol, including total cholesterol, highdensity lipoprotein cholesterol (HDL), LDL, triglycerides, plasma creatinine, and hemoglobin), and current chronic medical treatments taken by the patient for more than 7 days prior to inclusion in the registry. During annual follow-up visits the following information was collected: employment status, risk factors and life style, current symptoms, physical examination including heart rate, laboratory values (if available), current treatments and clinical events occurring since the last visit, e.g. all-cause death, fatal or non-fatal myocardial infarction (MI), fatal or nonfatal stroke, cardiovascular death, unstable angina, major bleeding, coronary angiography, and revascularization percutaneous coronary intervention (PCI) and $\mathrm{CABG}$, transient ischemic attack (TIA), hospitalization for congestive heart failure (CHF) and cardiovascular hospitalization. Completed eCRFs were electronically sent to the data management center in Glasgow (Robertson Centre for Biostatistics, University of Glasgow, UK) where checks for completeness, internal consistency and accuracy were run.

The study was performed in accordance with the principle of the Declaration of Helsinki and was approved by the National Research Ethics Service, Isle of Wright, Portsmouth and Southeast Hampshire Research Ethics Committee, UK. Approval was also obtained in Austria, in accordance with local regulations before recruitment of the first participant. All patients signed a written informed consent to participate, in accordance with national and local guidelines.

\section{Statistical analysis}

All data were collected and analyzed at an independent academic statistic center at the Robertson Centre for Biostatistics, University of Glasgow, UK which was responsible for data management, statistical analyses and storage of the data according to regulations. The main analyses were designed to describe patient characteristics at baseline and to estimate the annual cardiovascular event rates, and the outcome event rates by region and country. Baseline variables as well as parameters collected in the annual follow-up visits were summarized as means, standard deviations (SD), medians, interquartile ranges (IQR), and ranges for continuous data and as counts and percentages for categorical data. Summaries were provided for CLARIFY Austria and for CLARIFY Austria and subjects with angina. Statistical analysis was performed using the statistical package $\mathrm{R}$, version 3.1.2 [13]. Height and weight were used to calculate body mass index (BMI) in $\mathrm{kg} / \mathrm{m}^{2}$. Outcome was defined as occurrence of death and/or any cardiovascular events, such as MI or stroke during the observation period. Treatment targets were defined as normalized blood pressure $(<140 / 90 \mathrm{~mm} \mathrm{Hg})$, lowered LDL cholesterol plasma levels $(<0.7 \mathrm{~g} / \mathrm{l}$ or $<1.0 \mathrm{~g} / \mathrm{l})$, lowered HbAlc levels in diabetic patients $(<6.5 \%$ or $<7.0 \%)$, heart rate $\leq 60 \mathrm{bpm}$ in patients with anginal symptoms and smoking cessation.

\section{Results}

In Austria, 424 patients with stable CAD were included in the CLARIFY registry of which $75.0 \%$ were male and the mean age was $65.2 \pm 10.1$ years. The most frequent concomitant diseases were dyslipidemia and treated hypertension, $53.3 \%$ had a medical history of MI and $77.6 \%$ had had a PCI in the past and $33.5 \%$ of patients had a family history of premature CAD. Symptoms of chronic heart failure were present in $12.3 \%$. At baseline, mean BMI was $27.7 \pm 3.9 \mathrm{~kg} / \mathrm{m}^{2}$ and mean blood pressure was within the normal range. Resting heart rate measured by pulse palpation was $68.3 \pm$ $10.3 \mathrm{bpm}$ and by ECG $67.2 \pm 10.8 \mathrm{bpm}, 57.1 \%$ of patients were former or current smokers. The most predominant CAD risk factors were overweight and elevated LDL cholesterol plasma levels. Most patients reported regular light physical activities (52.8\%), 46 patients $(10.8 \%)$ with stable CAD were affected by anginal symptoms and $65.2 \%$ of these patients were male but the proportion of patients with anginal symptoms was higher in women than in men $(15.1 \%$ in women vs. $9.4 \%$ in men). Angina was classified as grade II according to the Canadian Cardiovascular Society (CCS) classification in most cases. Mean age of patients with anginal symptoms was $68.6 \pm 9.2$ years and dyslipidemia was the most frequently documented concomitant disease. Compared with the complete Austrian patient population, previous PCI was less common in patients with angina but symptoms of chronic heart failure were more common after previous PCI. In addition, patients with angina showed a slightly higher mean BMI and higher mean heart rate. Overall, in $60.9 \%$ of patients with angina heart rate was $\geq 70 \mathrm{bpm}$. The most common risk factors were elevated LDL cholesterol plasma levels and overweight. In addition, $32.6 \%$ of patients with angina were former smokers and $28.3 \%$ current smokers (Table 1).

At baseline, the majority of patients were treated with lipid-lowering drugs (LLD) $(94.6 \%$, predominantly statins: $89.3 \%$ ), aspirin (86.6\%) and beta-blockers $(78.8 \%)$. Angiotensin-converting enzyme (ACE) inhibitors were used in $45.0 \%$ and $33.0 \%$ received diuretics. Trimetazidine and ranolazine were not used. 
original article

Table 1 Baseline characteristics Austrian

\begin{tabular}{|c|c|c|}
\hline Parameter & $\begin{array}{l}\text { Patients with stable CAD } \\
(N=424)\end{array}$ & $\begin{array}{l}\text { Patients with stable } C A D \text { and } \\
\text { angina }(N=46)\end{array}$ \\
\hline Age (mean years $\pm S D$ ) & $65.2(10.1)$ & $68.6(9.2)$ \\
\hline \multicolumn{3}{|l|}{ Gender $(N[\%])$} \\
\hline Male & $318(75.0)$ & $30(65.2)$ \\
\hline Female & $106(25.0)$ & $16(34.8)$ \\
\hline \multicolumn{3}{|l|}{ Employment } \\
\hline Employed full-time & $94(22.2)$ & $3(6.5)$ \\
\hline Employed half-time & $11(2.6)$ & $2(4.3)$ \\
\hline Unable to work & $3(0.7)$ & $0(0.0)$ \\
\hline Unemployed & $4(0.9)$ & $2(4.3)$ \\
\hline Retired & $310(73.1)$ & $38(82.6)$ \\
\hline Other & $2(0.5)$ & $1(2.2)$ \\
\hline \multicolumn{3}{|l|}{ Education } \\
\hline Primary school (or less) & $214(50.5)$ & $29(63.0)$ \\
\hline Secondary school & $169(39.9)$ & $16(34.8)$ \\
\hline College/University & $41(9.7)$ & $1(2.2)$ \\
\hline \multicolumn{3}{|c|}{ Concomitant diseases and lifestyle (N [\%]) } \\
\hline Family history of premature $C A D^{a}$ & $142(33.5)$ & $14(30.4)$ \\
\hline Treated hypertension & $333(78.5)$ & $40(87.0)$ \\
\hline Diabetes & $121(28.5)$ & $19(41.3)$ \\
\hline Dyslipidemia $^{b}$ & $375(88.4)$ & $42(91.3)$ \\
\hline PAD & $64(15.1)$ & $11(23.9)$ \\
\hline \multicolumn{3}{|l|}{ Alcohol intake, glasses per week } \\
\hline 0 & $99(23.3)$ & $14(30.4)$ \\
\hline$>0$ to $<20$ & $316(74.5)$ & $31(67.4)$ \\
\hline$>20$ & $9(2.1)$ & $1(2.2)$ \\
\hline \multicolumn{3}{|l|}{ Stimulant drinks } \\
\hline Coffee & $311(73.3)$ & $37(80.4)$ \\
\hline Tea & $29(6.8)$ & $6(13.0)$ \\
\hline Neither & 84 (19.8) & $3(6.5)$ \\
\hline \multicolumn{3}{|l|}{ Physical activity } \\
\hline None & $45(10.6)$ & $6(13.0)$ \\
\hline Light $^{\mathrm{C}}$ & $224(52.8)$ & $32(69.6)$ \\
\hline 1-2 times per week ${ }^{d}$ & 81 (19.1) & $7(15.2)$ \\
\hline$\geq 3$ times per week ${ }^{d}$ & $74(17.5)$ & $1(2.2)$ \\
\hline \multicolumn{3}{|l|}{ Medical history N (\%) } \\
\hline Myocardial infarction & $226(53.3)$ & $21(45.7)$ \\
\hline $\mathrm{PCl}$ & $329(77.6)$ & $31(67.4)$ \\
\hline CABG & $99(23.3)$ & $12(26.1)$ \\
\hline Abdominal aortic aneurysm & $10(2.4)$ & $1(2.2)$ \\
\hline Coronary stenosis ${ }^{\mathrm{e}}$ & $54(12.7)$ & $14(30.4)$ \\
\hline ICD & $6(1.4)$ & $0(0.0)$ \\
\hline Pacemaker & $7(1.7)$ & $1(2.2)$ \\
\hline Stroke & $17(4.0)$ & $5(10.9)$ \\
\hline TIA & $13(3.1)$ & $3(6.5)$ \\
\hline Hospitalization for CHF & $13(3.1)$ & $2(4.3)$ \\
\hline Atrial fibrillation/flutter & $39(9.2)$ & $4(8.7)$ \\
\hline Asthma/COPD & $52(12.3)$ & $12(26.1)$ \\
\hline
\end{tabular}




\begin{tabular}{|c|c|c|}
\hline Parameter & $\begin{array}{l}\text { Patients with stable CAD } \\
(N=424)\end{array}$ & $\begin{array}{l}\text { Patients with stable } C A D \text { and } \\
\text { angina }(N=46)\end{array}$ \\
\hline \multicolumn{3}{|l|}{ Current symptoms (N [\%]) } \\
\hline Angina & $46(10.8)$ & $46(100.0)$ \\
\hline \multicolumn{3}{|l|}{ CCS class (if angina) } \\
\hline 1 & $14(30.4)$ & $14(30.4)$ \\
\hline ॥ & $25(54.3)$ & $25(54.3)$ \\
\hline III & $7(15.2)$ & $7(15.2)$ \\
\hline CHF symptoms & $52(12.3)$ & $15(32.6)$ \\
\hline \multicolumn{3}{|l|}{ NYHA class (if CHF) } \\
\hline II & $45(86.5)$ & $13(86.7)$ \\
\hline III & $7(13.5)$ & $2(13.3)$ \\
\hline \multicolumn{3}{|l|}{ Measurements } \\
\hline Weight $[\mathrm{kg}]$ & 81.4 & 81.0 \\
\hline Height [cm] & 171.5 & 170.0 \\
\hline BMI, mean (SD) $\left[\mathrm{kg} / \mathrm{m}^{2}\right]$ & $27.7(3.9)$ & $28.0(4.9)$ \\
\hline Heart rate (by pulse palpation), mean (SD) [bpm] & $68.3(10.3)$ & $73.8(13.8)$ \\
\hline Heart rate (by pulse ECG), mean (SD) [bpm] & $67.2(10.8)$ & $72.0(14.3)$ \\
\hline Heart rate $\geq 70$ bpm (in angina patients) & - & $28(60.9)$ \\
\hline SBP, mean (SD), [mm Hg] & $133.8(16.6)$ & $135.3(18.2)$ \\
\hline DBP mean (SD), [mm Hg] & $80.0(9.1)$ & $80.4(10.7)$ \\
\hline Waist circumference, mean (SD), [cm] & $99.2(11.2)$ & $101.5(13.9)$ \\
\hline \multicolumn{3}{|l|}{ Risk factors (N (\%)) } \\
\hline Overweight $f$ & $327 / 424(77.1)$ & $34 / 46(73.9)$ \\
\hline Obesity ${ }^{9}$ & 99/424 (23.3) & $15 / 46(32.6)$ \\
\hline Smoking status, $\mathrm{N}$ & 424 & 46 \\
\hline Current & $56(13.2)$ & $13(28.3)$ \\
\hline Former & $186(43.9)$ & $15(32.6)$ \\
\hline Never & $182(42.9)$ & $18(39.1)$ \\
\hline Raised blood pressure $^{\mathrm{h}}$ & $175 / 424(41.3)$ & $23 / 46(50.0)$ \\
\hline Raised LDL cholesterol $1^{i}$ & $126 / 370(34.1)$ & $12 / 39(30.8)$ \\
\hline Raised LDL cholesterol $2^{j}$ & $301 / 370(81.4)$ & $31 / 39(79.5)$ \\
\hline Lowered HDL cholesterol $^{k}$ & $66 / 379(17.4)$ & $12 / 42(28.6)$ \\
\hline Raised $\mathrm{HbA1} \mathrm{C}^{\mathrm{I}}$ & $46 / 121(38.0)$ & $5 / 19(26.3)$ \\
\hline HR on palpation $\geq 70$ bpm $^{\mathrm{m}}$ & - & $28 / 46(60.9)$ \\
\hline 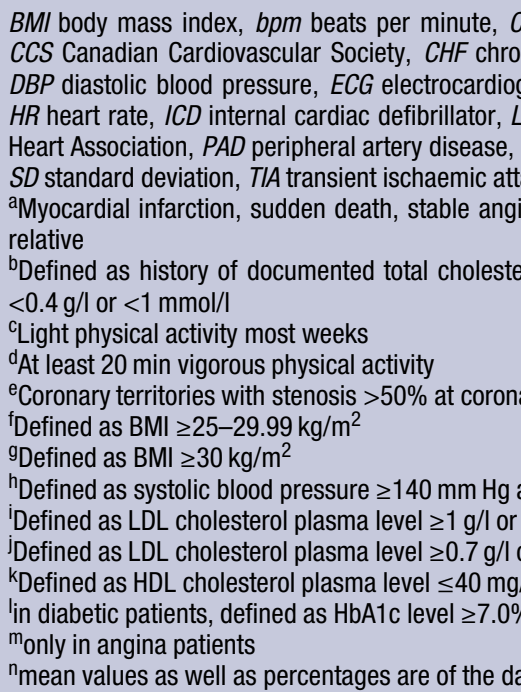 & $\begin{array}{l}\text { ronary artery bypass graft, } \\
\text { it failure, COPD chronic o } \\
\text { IbA1c glycated hemoglobin } \\
\text {-density lipoprotein, } N \text { num } \\
\text { cutaneous coronary interve } \\
\text { ge }<55 \text { years (men) or }<6 \\
\text { g/l or }>5.18 \mathrm{mmol} / / \text { or high } \\
\text { iography or required revasc } \\
\text { stolic blood pressure } \geq 90 \mathrm{~m} \\
\text { ol// } \\
\text { Imol// } \\
0 \mathrm{mmol} / / \mathrm{l}\end{array}$ & $\begin{array}{l}\text { coronary artery disease, } \\
\text { ctive pulmonary disease, } \\
\text { - high-density lipoprotein, } \\
\text { f patients, NYHA New York } \\
\text { SBP systolic blood pressure, } \\
\text { (women) in a first-degree } \\
\text { sity lipoprotein cholesterol } \\
\text { ation in medical history }\end{array}$ \\
\hline
\end{tabular}


The most frequently received other medications were proton pump inhibitors (PPI) and antidiabetic agents. During the 5 years of CLARIFY, there were only few alterations to these treatments and LLD (predominantly statins), aspirin and beta-blockers were the primary medications on follow-up. The usage of LLD was relatively stable, whereas the proportion of patients who received aspirin, beta-blockers or ACE inhibitors decreased over time. In contrast, the use of diuretics and angiotensin II (AT II) receptor inhibitors increased over time. With respect to other medications the proportion of patients who received nonsteroidal anti-inflammatory drugs (NSAIDs) slightly decreased. All other treatments remained the same (Table 2).
The primary treatment of patients with angina at baseline did not differ from the treatments of the whole Austrian patient population. Most of them received LLD (91.3\%, statins: $85.7 \%)$, aspirin (93.5\%), beta-blockers $(76.1 \%)$ and other antianginal agents (32.6\%); however, ivabradine, calcium antagonists, verapamil or dilitiazem, other antihypertensive agents as well as digoxin and derivates were more frequently used in patients with angina. The ACE inhibitors and diuretics were less frequently used. In addition, $45.7 \%$ of patients with anginal symptoms were treated with PPI, $32.6 \%$ with antidiabetic agents and $23.9 \%$ with NSAIDs. Throughout the follow-up period, treatments with aspirin, calcium antagonists and ivabradine saw a declining trend, whilst use of diuretics saw an in-

Table 2 Treatment of Austrian patients with stable CAD and Austrian patients with stable CAD and angina during observation $(N$ $[\%])^{\mathrm{a}}$

\begin{tabular}{|c|c|c|c|c|c|c|}
\hline Parameter & Baseline & 1st year & 2nd year & 3rd year & 4th year & 5th year \\
\hline \multicolumn{7}{|c|}{ Patients with stable CAD (N [\%]) } \\
\hline$N$ & 424 & 411 & 351 & 337 & 323 & 305 \\
\hline Aspirin & $367(86.6)$ & $333(82.2)$ & $268(79.1)$ & $248(75.8)$ & $231(74.5)$ & $213(73.2)$ \\
\hline Thienopyridines & $38(9.0)$ & $42(10.4)$ & $35(10.3)$ & $34(10.4)$ & $34(11.0)$ & $30(10.3)$ \\
\hline Other antiplatelet agent & $44(10.4)$ & $39(9.6)$ & $31(9.1)$ & $34(10.4)$ & $32(10.3)$ & $33(11.3)$ \\
\hline Oral anticoagulant & $46(10.8)$ & $44(10.9)$ & $45(13.3)$ & 45 (13.8) & $48(15.5)$ & $46(15.8)$ \\
\hline Beta-blocker & $334(78.8)$ & $304(75.1)$ & $249(73.5)$ & 235 (71.9) & $223(71.9)$ & $202(69.4)$ \\
\hline Ivabradine & $25(5.9)$ & $26(6.4)$ & $18(5.3)$ & $17(5.2)$ & $15(4.8)$ & $16(5.5)$ \\
\hline Calcium antagonists & 76 (17.9) & 74 (18.3) & $60(17.7)$ & $63(19.3)$ & $55(17.7)$ & $52(17.9)$ \\
\hline Verapamil or dilitiazem & $15(3.5)$ & $15(3.7)$ & $11(3.2)$ & $10(3.1)$ & $8(2.6)$ & $6(2.1)$ \\
\hline ACE inhibitors & $191(45.0)$ & $175(43.2)$ & $145(42.8)$ & $134(41.0)$ & $122(39.4)$ & $117(40.2)$ \\
\hline AT II receptor-blocker & $120(28.4)$ & $120(29.6)$ & $105(31.0)$ & $100(30.6)$ & $97(31.3)$ & $89(30.6)$ \\
\hline LLD & $401(94.6)$ & $378(93.3)$ & $316(93.2)$ & $300(91.7)$ & $284(91.6)$ & 267 (91.8) \\
\hline Statins (if LLD) & $358(89.3)$ & $321(84.9)$ & $261(82.6)$ & $246(82.0)$ & $230(81.0)$ & $213(79.8)$ \\
\hline Other antianginal agent & 50 (11.8) & $50(12.3)$ & 38 (11.2) & 40 (12.2) & 37 (11.9) & $32(11.0)$ \\
\hline Trimetazine & $0(0.0)$ & $0(0.0)$ & $0(0.0)$ & $0(0.0)$ & $0(0.0)$ & $0(0.0)$ \\
\hline Ranolazine & $0(0.0)$ & $1(0.2)$ & $2(0.6)$ & $4(1.2)$ & $4(1.3)$ & $3(1.0)$ \\
\hline Diuretics & $140(33.0)$ & $135(33.3)$ & $119(35.1)$ & $111(33.9)$ & $111(35.8)$ & $105(36.1)$ \\
\hline Other hypertensive agent & 47 (11.1) & $50(12.3)$ & 39 (11.5) & $36(11.0)$ & $34(11.0)$ & $29(10.0)$ \\
\hline Digoxin and derivates & $10(2.4)$ & $9(2.2)$ & $8(2.4)$ & $7(2.1)$ & $7(2.3)$ & $9(3.1)$ \\
\hline Amiodarone/dronedarone & $17(4.0)$ & $16(4.0)$ & $13(3.8)$ & $13(4.0)$ & $12(3.9)$ & $11(3.8)$ \\
\hline Other antiarrhythmics & $8(1.9)$ & $8(2.0)$ & $10(2.9)$ & $8(2.4)$ & $8(2.6)$ & $7(2.4)$ \\
\hline \multicolumn{7}{|l|}{ Other medication } \\
\hline NSAIDs & $44(10.4)$ & $44(10.9)$ & 35 (10.3) & $28(8.6)$ & $27(8.7)$ & $22(7.6)$ \\
\hline Antidiabetic agents & $82(19.3)$ & 76 (18.8) & $56(16.5)$ & 56 (17.2) & 54 (17.4) & $53(18.4)$ \\
\hline PPI & $151(35.6)$ & $144(35.6)$ & $114(33.5)$ & $106(32.6)$ & 109 (35.2) & $99(34.4)$ \\
\hline THoR & 48 (11.3) & $47(11.6)$ & 40 (11.8) & $39(12.0)$ & $36(11.6)$ & $31(10.8)$ \\
\hline $\mathrm{HoR}$ & $1(0.2)$ & $1(0.2)$ & $1(0.3)$ & $1(0.3)$ & $1(0.3)$ & $1(0.3)$ \\
\hline Drug for ED & $8(1.9)$ & $8(2.0)$ & $5(1.5)$ & $5(1.5)$ & $4(1.3)$ & $3(1.0)$ \\
\hline \multicolumn{7}{|c|}{ Patients with stable $C A D$ and angina } \\
\hline$N$ & 46 & 35 & 25 & 14 & 16 & 7 \\
\hline Aspirin & $43(93.5)$ & $28(80.0)$ & $20(80.0)$ & $13(92.9)$ & $13(81.2)$ & $5(71.4)$ \\
\hline Thienopyridines & $4(8.7)$ & $6(17.1)$ & $7(28.0)$ & $1(7.1)$ & $2(12.5)$ & $0(0.0)$ \\
\hline Other antiplatelet agent & $2(4.3)$ & $2(5.7)$ & $1(4.0)$ & $1(7.1)$ & $1(6.2)$ & $1(14.3)$ \\
\hline Oral anticoagulant & $5(10.9)$ & $5(14.3)$ & $4(16.0)$ & $3(21.4)$ & $3(18.8)$ & $0(0.0)$ \\
\hline Beta-blocker & $35(76.1)$ & $18(51.4)$ & $20(80.0)$ & $11(78.6)$ & $13(81.2)$ & $5(71.4)$ \\
\hline
\end{tabular}


Table 2 (Continued)

\begin{tabular}{|c|c|c|c|c|c|c|}
\hline Parameter & Baseline & 1st year & 2nd year & 3rd year & 4th year & 5th year \\
\hline Ivabradine & $11(23.9)$ & $8(22.9)$ & $2(8.0)$ & $1(7.1)$ & $0(0.0)$ & $0(0.0)$ \\
\hline Calcium antagonists & $14(30.4)$ & $11(31.4)$ & $4(16.0)$ & $4(28.6)$ & $3(18.8)$ & $2(28.6)$ \\
\hline Verapamil or dilitiazem & $4(8.7)$ & $5(14.3)$ & $2(8.0)$ & $1(7.1)$ & $1(6.2)$ & $0(0.0)$ \\
\hline ACE inhibitors & $18(39.1)$ & $14(40.0)$ & $11(44.0)$ & $6(42.9)$ & $5(31.2)$ & $3(42.9)$ \\
\hline AT II receptor-blocker & $15(32.6)$ & $14(40.0)$ & $7(28.0)$ & $7(50.0)$ & $7(43.8)$ & $1(14.3)$ \\
\hline LLD & 42 (91.3) & $32(91.4)$ & $23(92.0)$ & $14(100.0)$ & 15 (93.8) & $7(100.0)$ \\
\hline Statins (if LLD) & $36(85.7)$ & $25(78.1)$ & $17(73.9)$ & $7(50.0)$ & $10(66.7)$ & $4(57.1)$ \\
\hline Other antianginal agent & $15(32.6)$ & $12(34.3)$ & $9(36.0)$ & $8(57.1)$ & $7(43.8)$ & $3(42.9)$ \\
\hline Trimetazine & $0(0.0)$ & $0(0.0)$ & $0(0.0)$ & $0(0.0)$ & $0(0.0)$ & $0(0.0)$ \\
\hline Ranolazine & $0(0.0)$ & $1(2.9)$ & $2(8.0)$ & $3(21.4)$ & $1(6.2)$ & $1(14.3)$ \\
\hline Diuretics & $14(30.4)$ & $16(45.7)$ & $12(48.0)$ & $9(64.3)$ & $9(56.2)$ & $3(42.9)$ \\
\hline Other hypertensive agent & $7(15.2)$ & $8(22.9)$ & $4(16.0)$ & $4(28.6)$ & $3(18.8)$ & $1(14.3)$ \\
\hline Digoxin and derivates & $3(6.5)$ & $2(5.7)$ & $2(8.0)$ & $1(7.1)$ & $1(6.2)$ & $0(0.0)$ \\
\hline Amiodarone/dronedarone & $2(4.3)$ & $3(8.6)$ & $1(4.0)$ & $0(0.0)$ & $0(0.0)$ & $1(14.3)$ \\
\hline Other antiarrhythmics & $0(0.0)$ & $0(0.0)$ & $2(8.0)$ & $0(0.0)$ & $0(0.0)$ & $0(0.0)$ \\
\hline \multicolumn{7}{|l|}{ Other medication } \\
\hline NSAIDs & $11(23.9)$ & $6(17.1)$ & $3(12.0)$ & $2(14.3)$ & $1(6.2)$ & $1(20.0)$ \\
\hline Antidiabetic agents & $15(32.6)$ & $5(14.3)$ & $3(12.0)$ & $1(7.1)$ & $2(12.5)$ & $0(0.0)$ \\
\hline PPI & $21(45.7)$ & $15(42.9)$ & $9(36.0)$ & $6(42.9)$ & $7(43.8)$ & $3(60.0)$ \\
\hline $\mathrm{THOR}$ & $6(13.0)$ & $5(14.3)$ & $4(16.0)$ & $2(14.3)$ & $1(6.2)$ & $0(0.0)$ \\
\hline $\mathrm{HoR}$ & $0(0.0)$ & $0(0.0)$ & $0(0.0)$ & $0(0.0)$ & $0(0.0)$ & $0(0.0)$ \\
\hline Drug for ED & $1(2.2)$ & $1(2.9)$ & $1(4.0)$ & $0(0.0)$ & $0(0.0)$ & $0(0.0)$ \\
\hline
\end{tabular}

creasing trend. The proportion of patients who were treated with LLD was very stable, but treatment with statins decreased. In addition, there was also a decline in the use of antidiabetic agents as well as thyroid hormone replacement therapies (Table 2).

Analysis of patient status over 5 years of CLARIFY follow-up showed no changes in mean body weight and mean BMI as well as no changes in systolic and diastolic blood pressure as well as heart rate. The prevalence of overweight, obesity and elevated LDL cholesterol plasma levels declined, but there was an increase in the proportion of patients with low HDL cholesterol plasma levels. Overall the proportion of smoking patients decreased, and only $1.9 \%$ of patients who did not smoke at baseline were current smokers in the 5 th year (Table 3).

The proportion of patients with angina decreased from $8.6 \%$ after the 1 st year to $2.3 \%$ in the 5 -year follow-up. In addition, these patients showed a decrease in mean body weight and mean BMI. Furthermore, there was a decline in mean heart rate, and a heart rate $\geq 70 \mathrm{bpm}$ was less common. In contrast, blood pressure increased and elevated blood pressure was more common in year 5 of CLARIFY compared to the year 1 assessment. The LDL cholesterol plasma levels did not change and the proportion of patients with lower HDL cholesterol plasma levels was growing, similar to the total Austrian patient population (Table 3).
At the end of the observation period, blood pressure was normalized in $58.5 \%$ of outpatients with stable CAD and treated hypertension, which was defined as SBP $<140 \mathrm{~mm} \mathrm{Hg}$ and $\mathrm{DBP}<90 \mathrm{~mm} \mathrm{Hg}$. Of the patients $70.4 \%$ had LDL cholesterol plasma levels below $1.0 \mathrm{~g} / \mathrm{l}(2.6 \mathrm{mmol} / \mathrm{l})$ and $24.5 \%$ had LDL cholesterol plasma levels $<0.7 \mathrm{~g} / \mathrm{l}(1.8 \mathrm{mmol} / \mathrm{l}), 42.1 \%$ of current smokers at baseline had stopped smoking during CLARIFY, $42.9 \%$ of patients with anginal symptoms achieved a heart rate $\leq 60 \mathrm{bpm}$ and $26.0 \%$ of diabetic patients could reduce their HbAlc levels below 6.5\% (Table 4).

The primary outcome, defined as the composite of cardiovascular death, MI or stroke over 5 years occurred in $7.1 \%$ of Austrian patients and $8.7 \%$ of patients from the rest of the CLARIFY population. Cardiovascular death was observed in $3.5 \%$ of Austrian patients and $5.0 \%$ of patients in the rest of CLARIFY, all-cause death in $5.9 \%$ and $7.9 \%$ of each population, respectively and hospitalization for heart failure in $3.5 \%$ and $5.1 \%$. The frequency of MI (fatal or nonfatal) and stroke (fatal or non fatal) was very similar between the populations (MI was observed in 3.3\% and $3.4 \%$ of each population and stroke was observed in $1.9 \%$ and $2.1 \%$ of each population) (Table 5).

European outpatients with CAD had a slightly lower heart rate than Austrian patients. The same could be found in patients with anginal symptoms at baseline 
Table 3 Patient characteristics of Austrian patients with stable CAD and Austrian patients with stable CAD and angina during observation

\begin{tabular}{|c|c|c|c|c|c|}
\hline Parameter & 1st year & 2nd year & 3rd year & 4th year & 5th year \\
\hline \multicolumn{6}{|l|}{ Patients with stable CAD (N [\%]) } \\
\hline$N$ & 411 & 351 & 337 & 323 & 305 \\
\hline Weight [kg] & $81.6(13.8)$ & $81.9(13.5)$ & $82.1(14.7)$ & $81.9(13.5)$ & $81.4(14.0)$ \\
\hline BMI, mean (SD) $\left[\mathrm{kg} / \mathrm{m}^{2}\right]$ & $27.7(4.0)$ & $27.9(4.0)$ & $27.9(4.3)$ & $27.7(3.9)$ & $27.6(3.9)$ \\
\hline HR (palpation), mean (SD) [bpm] & $66.7(9.6)$ & $66.2(9.9)$ & $66.4(11.3)$ & $66.4(10.3)$ & $67.3(11.3)$ \\
\hline HR (ECG), mean (SD) [bpm] & $66.0(10.0)$ & $65.8(9.8)$ & $66.1(11.5)$ & $66.5(11.3)$ & $67.0(11.0)$ \\
\hline $\mathrm{SBP}$, mean (SD), [mm Hg] & $133.4(17.4)$ & $132.9(18.8)$ & $133.3(17.1)$ & $134.3(17.9)$ & $133.7(16.8)$ \\
\hline DBP mean (SD), [mm Hg] & $79.3(9.3)$ & $78.5(9.5)$ & $78.8(9.4)$ & $78.9(9.7)$ & $78.4(9.4)$ \\
\hline Waist circumference, mean (SD), [cm] & $99.3(12.0)$ & $98.6(11.5)$ & $99.7(13.1)$ & $99.4(11.2)$ & $100.1(13.6)$ \\
\hline Overweight (\%) ${ }^{\mathrm{a}}$ & $305(76.2)$ & $270(78.3)$ & $253(76.0)$ & $232(75.6)$ & $224(75.7)$ \\
\hline Obesity $(\%)^{b}$ & $98(24.5)$ & $85(24.6)$ & $78(23.4)$ & $74(24.1)$ & $67(22.6)$ \\
\hline \multicolumn{6}{|l|}{ Smoking status (\%) } \\
\hline Current & $45(11.0)$ & $35(10.1)$ & $33(9.9)$ & $29(9.1)$ & $27(9.1)$ \\
\hline Former & $189(46.3)$ & $157(45.2)$ & $153(45.7)$ & $135(42.5)$ & $114(38.3)$ \\
\hline Never & $174(42.6)$ & $155(44.7)$ & $149(44.5)$ & $154(48.4)$ & $157(52.7)$ \\
\hline Raised blood pressure $(\%)^{c}$ & $163(40.8)$ & $125(36.2)$ & $120(36.0)$ & $129(42.0)$ & $117(39.5)$ \\
\hline Raised LDL cholesterol $1(\%)^{d}$ & $120(36.4)$ & $96(34.9)$ & $86(34.1)$ & $72(30.0)$ & $69(30.5)$ \\
\hline Raised LDL cholesterol $2(\%)^{\mathrm{e}}$ & $274(83.0)$ & $225(81.8)$ & $206(81.7)$ & $193(80.4)$ & $173(76.5)$ \\
\hline Lowered HDL cholesterol $(\%)^{\dagger}$ & $58(16.6)$ & $48(16.8)$ & $52(19.3)$ & $53(21.2)$ & $55(23.3)$ \\
\hline Raised $\mathrm{HbA} 1 \mathrm{c}(\%)^{\mathrm{g}}$ & $33(28.0)$ & $22(23.2)$ & $32(35.6)$ & $30(36.1)$ & $24(31.2)$ \\
\hline Smoking initiation $(\%)^{\mathrm{h}}$ & $6(1.7)$ & $4(1.3)$ & $5(1.7)$ & $4(1.4)$ & $5(1.9)$ \\
\hline \multicolumn{6}{|l|}{ Patients with stable $C A D$ and angina } \\
\hline$N(\%)$ & $35(8.6)$ & $25(7.2)$ & $14(4.2)$ & $16(5.0)$ & $7(2.3)$ \\
\hline Weight [kg] & $79.5(15.3)$ & $81.9(13.0)$ & $79.7(12.9)$ & $76.9(12.1)$ & $71.7(15.3)$ \\
\hline BMI, mean (SD) $\left[\mathrm{kg} / \mathrm{m}^{2}\right]$ & $26.9(4.1)$ & $27.1(3.5)$ & $27.2(3.0)$ & $27.6(4.3)$ & $24.0(4.4)$ \\
\hline HR (palpation), mean (SD) [bpm] & $69.5(11.4)$ & $65.3(12.0)$ & $71.1(16.9)$ & $63.8(9.0)$ & $62.3(4.8)$ \\
\hline HR (ECG), mean (SD) [bpm] & $68.5(10.2)$ & $65.1(13.5)$ & $68.4(16.3)$ & $63.9(9.3)$ & $63.3(6.4)$ \\
\hline $\mathrm{HR} \geq 70$ bpm (palpation) & $17(48.6)$ & $5(20.0)$ & $6(42.9)$ & $3(18.8)$ & $1(14.3)$ \\
\hline $\mathrm{SBP}$, mean (SD), [mm Hg] & $129.8(16.2)$ & $131.8(22.3)$ & $140.0(20.2)$ & $136.8(20.7)$ & $138.0(19.1)$ \\
\hline DBP mean (SD), [mm Hg] & $77.2(10.3)$ & $78.7(8.4)$ & $79.7(13.5)$ & $72.8(11.3)$ & $81.0(14.8)$ \\
\hline Waist circumference, mean (SD), [cm] & $97.9(13.5)$ & $101.0(11.7)$ & $99.6(11.6)$ & $99.7(15.1)$ & $94.7(12.9)$ \\
\hline Overweight (\%) ${ }^{\mathrm{a}}$ & $24(68.6)$ & 19 (79.2) & $11(78.6)$ & $10(66.7)$ & $3(50.0)$ \\
\hline Obesity $(\%)^{b}$ & $9(25.7)$ & $4(16.7)$ & $2(14.3)$ & $5(33.3)$ & $1(16.7)$ \\
\hline
\end{tabular}

but during the years of CLARIFY, the heart rate of Austrian patients with angina showed a stronger decline than the heart rate of patients with angina in the rest of Europe. In addition, the proportion of patients with heart rates above $70 \mathrm{bpm}$ was lower among Austrian patients with angina at the end of documentation and relatively more Austrian patients with angina achieved a heart rate below $60 \mathrm{bpm}$. With respect to therapeutic heart rate-modulators, it could be seen that Austrian patients as well as patients from other European countries were primarily treated with beta-blockers. Differences could be found in the usage of ivabradine. Patients from other European countries were more frequently treated with ivabradine than Austrian patients, especially patients with angina. Verapamil or dilitiazem as well as digoxin and derivates played only a minor role in both (Table 6).

\section{Discussion}

This analysis describes disease management and clinical outcome of Austrian outpatients with stable CAD as well as risk factors and life style management over 5 years of the CLARIFY registry. Main objectives of CAD management are to reduce morbidity and mortality and improve quality of life. Life style interventions, such as smoking cessation, reduction of body weight, increase in physical activities, control of blood pressure, cholesterol plasma levels and diabetes as well as the use of selective medications reduce the risk of cardiovascular events and improve survival [14, 15]. The aims of pharmacological management of stable CAD patients are to reduce angina and prevent cardiovascular events [17] and three classes of medication are shown to be essential in the treatment of CAD: lipid-lowering agents, antihypertensive 
Table 3 (Continued)

\begin{tabular}{|c|c|c|c|c|c|}
\hline Parameter & 1st year & 2nd year & 3rd year & 4th year & 5th year \\
\hline \multicolumn{6}{|l|}{ Smoking status $N(\%)$} \\
\hline Current & $5(14.3)$ & $2(8.0)$ & $1(7.1)$ & 2 (12.5) & $1(14.3)$ \\
\hline Former & $14(40.0)$ & $13(52.0)$ & $6(42.9)$ & $5(31.2)$ & $3(42.9)$ \\
\hline Never & $16(45.7)$ & $10(40.0)$ & $7(50.0)$ & $9(56.2)$ & $3(42.9)$ \\
\hline Raised blood pressure $(\%)^{c}$ & $9(25.7)$ & $8(33.3)$ & $7(50.0)$ & $8(53.3)$ & $3(50.0)$ \\
\hline Raised LDL cholesterol $1(\%)^{d}$ & $14(50.0)$ & $6(30.0)$ & $3(25.0)$ & $3(25.0)$ & $2(50.0)$ \\
\hline Raised LDL cholesterol $2(\%)^{\mathrm{e}}$ & $25(89.3)$ & $16(80.0)$ & $9(75.0)$ & $8(66.7)$ & $4(100.0)$ \\
\hline Lowered HDL cholesterol (\%) ${ }^{\dagger}$ & $5(16.1)$ & $5(23.8)$ & $3(25.0)$ & $4(28.6)$ & $1(25.0)$ \\
\hline Raised HbA1c (\%) ${ }^{g}$ & $3(30.0)$ & $2(25.0)$ & $2(66.7)$ & $0(0.0)$ & $0(0.0)$ \\
\hline Started smoking $(\%)^{\mathrm{h}}$ & $0(0.0)$ & $0(0.0)$ & $0(0.0)$ & $0(0.0)$ & $1(14.3)$ \\
\hline \multicolumn{6}{|c|}{ 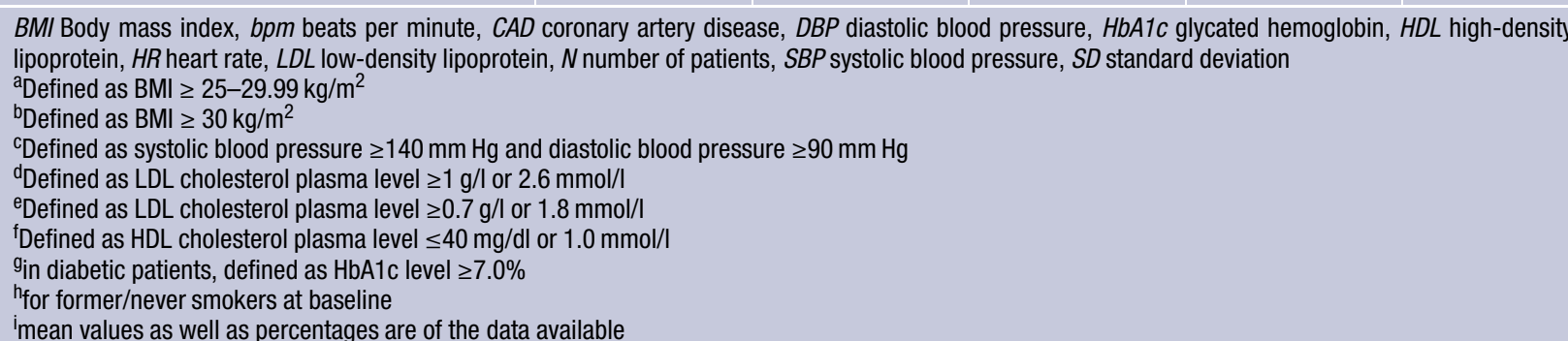 } \\
\hline
\end{tabular}

Table 4 Treatment targets that were met 5 years after study inclusion in Austrian patients with stable CAD $(N,[\%])^{\mathrm{h}}$

\begin{tabular}{|c|c|}
\hline Variable & Patients with stable $\mathrm{CAD}(N=305)$ \\
\hline Normalized blood pressure ${ }^{\mathrm{a}}$ & 134/229 (58.5) \\
\hline Lowered LDL cholesterol $1^{\mathrm{b}}$ & 138/196 (70.4) \\
\hline Lowered LDL cholesterol ${ }^{\mathrm{C}}$ & $48 / 196(24.5)$ \\
\hline Lowered HbA1c $1^{d}$ & $33 / 77$ (42.9) \\
\hline Lowered HbA1c $2^{\mathrm{e}}$ & $20 / 77(26.0)$ \\
\hline$H R \leq 60 \mathrm{bpm}^{\dagger}$ & $3 / 7(42.9)$ \\
\hline Smoking cessation ${ }^{9}$ & $16 / 38(42.1)$ \\
\hline \multicolumn{2}{|c|}{ 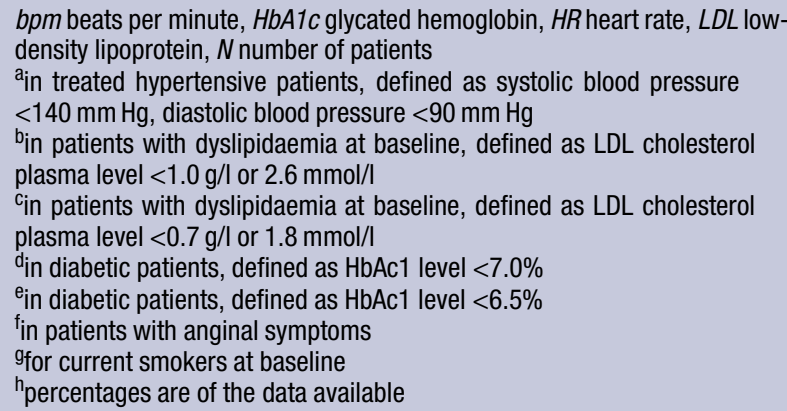 } \\
\hline
\end{tabular}

agents and antiplatelet agents [18]. Risk factors found in Austrian outpatients with stable CAD were smoking, overweight, hypertension, raised LDL cholesterol plasma levels, elevated heart rate and a low level of physical activity [16, 18]. Anginal symptoms were more common in women than in men, which is consistent with the data of the whole CLARIFY population as well as the Euro Heart Survey [16, 20, 21]. It was shown that women present with angina twice as often as men [17]. Moreover, angina is the most frequent manifestation of CAD in women [22]. Interestingly, Austrian patients with angina were older than patients without angina, which contrasts with the results of the analysis of the international CLARIFY population where patients with angina were slightly younger than patients without angina. This could be the result of the small sample size of Austrian patients with angina compared to the patients with anginal symptoms in the total CLARIFY registry [6]. During the 5 years of observation there were life style improvements but recommended goals were not achieved by the majority of patients. It is known that smoking cessation has a positive effect on the prognosis of coronary disease [14, 23-25] and may be the most effective of all preventive measures. Smoking cessation is associated with a $36 \%$ reduction of mortality after MI [14], $13.2 \%$ of patients were current smokers at baseline, after 5 years $42.1 \%$ of these patients had stopped smoking. Another strong risk factor for cardiovascular complications is diabetes mellitus [14, 19, 26]. In the present study, diabetes had been previously diagnosed in $28.5 \%$ of all Austrian patients with CAD and in $41.3 \%$ of patients with angina. Current guidelines recommend disease management with $\mathrm{HbAcl}$ below $7.0 \%$ [17]. While most diabetic patients had an HbAc1 level below $7.0 \%$ at baseline, the proportion of patients with $\mathrm{HbAcl}>7.0 \%$ remained constant during the observation period with less than half of those patients achieving treatment goals at 5 years. Overweight and obesity are risk factors for an increase in all-cause mortality in general and cardiovascular mortality in particular, because both have an adverse effect on blood pressure, dyslipidemia and glucose metabolism [14, 17, 23]. In the present analyses, overweight was present in approximately three quarters of patients over the whole observation period and the presence of obesity only slightly decreased 
Table 5 Clinical events in Austrian patients and all CLARIFY patients ${ }^{\mathrm{a}}$ with stable CAD $(N,[\%])^{\mathrm{c}}$

\begin{tabular}{|c|c|c|}
\hline Event & $\begin{array}{l}\text { Austrian patients with stable } \\
\mathrm{CAD}(N=424)\end{array}$ & $\begin{array}{l}\text { CLARIFY patients with stable } \\
\text { CAD }(N=31954)\end{array}$ \\
\hline All cause death & $25(5.9)$ & 2519 (7.9) \\
\hline Cardiovascular death & $15(3.5)$ & $1604(5.0)$ \\
\hline Non-cardiovascular death & $10(2.4)$ & $915(2.9)$ \\
\hline MI (fatal or non-fatal) & $14(3.3)$ & $1092(3.4)$ \\
\hline Stroke (fatal or non-fatal) & $8(1.9)$ & $678(2.1)$ \\
\hline Cardiovascular death or non-fatal MI & $24(5.7)$ & $2329(7.3)$ \\
\hline Cardiovascular death, non-fatal MI or non-fatal stroke & $30(7.1)$ & $2777(8.7)$ \\
\hline Non-fatal MI & $9(2.1)$ & $786(2.5)$ \\
\hline Non-fatal stroke & $6(1.4)$ & $525(1.6)$ \\
\hline Unstable angina & $34(8.0)$ & $3405(10.7)$ \\
\hline Major bleeding & $9(2.1)$ & $437(1.4)$ \\
\hline Coronary angiography & $67(15.8)$ & $4562(14.3)$ \\
\hline $\mathrm{PCl}$ & $34(8.0)$ & $2106(6.6)$ \\
\hline CABG & $6(1.4)$ & $429(1.3)$ \\
\hline Revascularization (PCl or CABG) & $39(9.2)$ & $2487(7.8)$ \\
\hline TIA & $5(1.2)$ & $823(2.6)$ \\
\hline Hospitalization for CHF & $15(3.5)$ & $1632(5.1)$ \\
\hline $\begin{array}{l}\text { Cardiovascular death, non-fatal MI, non-fatal stroke or } \\
\text { revascularization }\end{array}$ & $30(7.1)$ & $2777(8.7)$ \\
\hline MI (fatal or non-fatal) or revascularization & $42(9.9)$ & $3068(9.6)$ \\
\hline $\begin{array}{l}\text { MI (fatal or non-fatal) or revascularization or unstable } \\
\text { angina }\end{array}$ & $56(13.2)$ & $5097(16.0)$ \\
\hline Cardiovascular hospitalization & $124(29.2)$ & $9713(30.4)$ \\
\hline
\end{tabular}

from $23.3 \%$ at baseline to $22.6 \%$ at 5 years. Mean body weight, BMI as well as waist circumferences did not change. Dyslipidemia was present in the vast majority of Austrian patients with stable CAD. It is recommended that dyslipidemia should be managed according to the lipid guidelines with pharmacological aid and life style interventions. Investigations have shown that intensive LDL cholesterol lowering reduces the risk of cardiovascular events in patients with CAD. Moreover, it is associated with reduction in plaque volume [27-29]. Treatment goals of current guidelines are LDL cholesterol plasma levels below $1.8 \mathrm{mmol} / \mathrm{l}(<0.7 \mathrm{~g} / \mathrm{l})$ or a more than $50 \%$ reduction of LDL cholesterol plasma levels when the target level cannot be achieved [17]. More than $90 \%$ of Austrian patients were treated with LLD, which is clearly more than found in EUROASPIRE II or the Euro Heart Survey $[14,15]$. Although LLDs were widely used, target LDL cholesterol levels $<1.8 \mathrm{mmol} / 1$ were achieved by only $24.5 \%$ of patients. Nevertheless, $70.4 \%$ of patients could lower the LDL cholesterol plasma level below $2.6 \mathrm{mmol} / \mathrm{l}$. A meta-analysis demonstrated that LDL cholesterol lowering by $40 \mathrm{mg} / \mathrm{dl}(1.04 \mathrm{mmol} / \mathrm{l})$ resulted in a $23 \%$ decrease in CAD mortality [18]; therefore, lipid control is an unmet need that may be improved by the use of the novel proprotein con- vertase subtilisin/kexin type 9 (PCSK9) inhibitors alirocumab and evolocumab.

Elevated blood pressure is a major risk factor for CAD, heart failure and cerebrovascular disease [20]. Furthermore, high blood pressure following myocardial infarction is associated with an increased risk of reinfarction, stroke and cardiovascular death [14, 30]. Almost half of the Austrian patients with stable $\mathrm{CAD}$ and half of the patients with angina had elevated blood pressure and were treated with antihypertensive agents. Among these patients, $58.5 \%$ had a blood pressure of $<140 / 90 \mathrm{~mm} \mathrm{Hg}$ at the end of the observation period, which is recommended as treatment goal [17]; however, more intensive lowering of blood pressure below a systolic level of $120 \mathrm{~mm} \mathrm{Hg}$ is associated with both a decrease of cardiovascular events but also blood pressure-related adverse outcomes [31]. Analyses of the international CLARIFY cohort showed that an elevated blood pressure $>140 / 90 \mathrm{~mm} \mathrm{Hg}$ was associated with an increased risk of stroke but SBP $<120 \mathrm{~mm} \mathrm{Hg}$ and DBP $<70 \mathrm{~mm} \mathrm{Hg}$ were also associated with an increased risk of cardiovascular events [32]. Thus, there is still uncertainty about the optimal blood pressure target; however, taking the currently recommended treatment target of $<140 / 90 \mathrm{~mm} \mathrm{Hg}$, hypertension is not controlled in more than $40 \%$ of Austrian patients with stable CAD despite the broad 
Table 6 Heart rate and heart rate-modulating medications in European ${ }^{\mathrm{a}}$ patients with stable CAD and European ${ }^{\mathrm{a}}$ patients with stable CAD and angina during observation ${ }^{\mathrm{b}}$

\begin{tabular}{|c|c|c|c|c|c|c|}
\hline Parameter & Baseline & 1st year & 2nd year & 3rd year & 4th year & 5th year \\
\hline \multicolumn{7}{|l|}{ Patients with stable CAD (N, [\%]) } \\
\hline & 17,902 & 17,038 & 16,089 & 14,851 & 13,289 & 11,954 \\
\hline HR, mean (SD) palpation (bpm) & $67.3(10.5)$ & $66.3(9.8)$ & $65.9(9.7)$ & $66.0(9.6)$ & $66.1(9.5)$ & $66.0(9.1)$ \\
\hline HR, mean (SD) ECG (bpm) & $66.5(11.2)$ & $65.7(10.4)$ & $65.3(10.3)$ & $65.4(10.2)$ & $65.6(10.2)$ & $65.5(9.8)$ \\
\hline \multicolumn{7}{|l|}{ Medications ( $N, \%)$} \\
\hline Beta-blocker & $14,077(78.7)$ & $12,900(76.5)$ & $11,917(75.9)$ & $10,910(75.9)$ & 9647 (76.5) & $8568(76.7)$ \\
\hline Ivabradine & $2852(15.9)$ & $3182(18.9)$ & 3289 (20.9) & 3210 (22.3) & $2965(23.5)$ & $2695(24.1)$ \\
\hline Verapamil or dilitiazem & $914(5.1)$ & $807(4.8)$ & $728(4.6)$ & $603(4.2)$ & $472(3.7)$ & $407(3.6)$ \\
\hline Digoxin and derivates & $381(2.1)$ & $374(2.2)$ & $347(2.2)$ & $338(2.3)$ & $292(2.3)$ & $262(2.3)$ \\
\hline \multicolumn{7}{|c|}{ Patients with stable $C A D$ and angina } \\
\hline$(N,[\%])$ & 4873 (27.2) & 3599 (21.3) & $3271(20.6)$ & $2929(19.9)$ & $2613(19.9)$ & $2384(20.3)$ \\
\hline HR, mean (SD) palpation (bpm) & $69.7(10.8)$ & $68.2(9.5)$ & $67.4(9.3)$ & $67.3(8.9)$ & $66.9(8.8)$ & $66.9(8.3)$ \\
\hline HR, mean (SD) ECG (bpm) & $68.8(11.6)$ & $67.3(10.2)$ & $66.5(9.9)$ & $66.2(9.6)$ & $66.1(9.6)$ & $66.1(8.9)$ \\
\hline $\mathrm{HR} \geq 70$ bpm palpation $(N, \%)$ & $2351(48.2)$ & $1495(41.5)$ & $1218(37.2)$ & $1086(37.1)$ & $866(33.1)$ & $755(31.7)$ \\
\hline $\mathrm{HR} \leq 60 \mathrm{bpm}$ palpation $(\mathrm{N}, \%)$ & $1102(22.6)$ & 860 (23.9) & $827(25.3)$ & $745(25.4)$ & $696(26.6)$ & $570(23.9)$ \\
\hline \multicolumn{7}{|l|}{ Medications $(N, \%)$} \\
\hline Beta-blocker & 3960 (81.3) & 2944 (81.8) & $2652(81.5)$ & $2381(82.0)$ & $2123(82.4)$ & $1917(81.9)$ \\
\hline Ivabradine & $1417(29.1)$ & $1142(31.7)$ & $1156(35.5)$ & $1110(38.2)$ & $1030(40.0)$ & $925(39.5)$ \\
\hline Verapamil or dilitiazem & $251(5.2)$ & $156(4.3)$ & $135(4.1)$ & $107(3.7)$ & $76(3.0)$ & $81(3.5)$ \\
\hline Digoxin and derivates & $102(2.1)$ & $89(2.5)$ & $89(2.7)$ & $78(2.7)$ & $63(2.4)$ & $55(2.4)$ \\
\hline
\end{tabular}

use of antihypertensive agents. A total of $69-79 \%$ of patients received beta-blockers as first-line antihypertensive agents and $40-45 \%$ were treated with ACE inhibitors. The ACE inhibitors are primarily used in patients with CAD following myocardial infarction, in diabetic patients and patients with left ventricular dysfunction but all other patients with CAD should also receive ACE inhibitors once beta-blocker therapy has been established [18, 33]. Of the patients 28-30\% were treated with AT II receptor blockers and finally approximately $17 \%$ received calcium antagonists, which are mainly used if beta-blockers are not tolerated [34]. Heart rate is a primary determinant of myocardial ischemia [9, 10, 12]. Heart rate lowering drugs have clear anti-ischemic and anti-anginal effects in patients with CAD [35], justifying a recommended target heart rate of $55-60 \mathrm{bpm} \mathrm{[12].} \mathrm{This}$ target was not achieved by the majority of Austrian patients. Moreover, and in contrast to patients in the rest of Europe, there was no reduction in mean heart rate over 5 years in Austrian patients with stable CAD despite use of beta-blockers in majority of patients; therefore, there is still much room for improvement in HR control in the management of stable CAD. In patients with angina and elevated HR addition of ivabradine is one option to reduce HR without an effect on blood pressure, thus achieving further antianginal and anti-ischemic efficacy. The INITIATIVE study showed that ivabradine is a potent anti-angi- nal agent and is as effective as atenolol in patients with angina [36]. Other investigations such as the ASSOCIATE study or the ADDITIONS study showed that ivabradine also improves symptoms and quality of life when combined with beta-blockers in patients with stable angina. Moreover, ivabradine produced additional anti-anginal and anti-ischemic benefits without untoward effects on tolerability [37-40]. Approximately one quarter of European CAD patients and almost $40 \%$ of European patients with angina received ivabradine as part of their CAD management. In contrast, only approximately $6 \%$ of Austrian patients with stable CAD received this medication. Even in the case of patients with anginal symptoms ivabradine was only rarely used. In years 4 and 5 of follow-up no patient with angina was treated with ivabradine; however, patient numbers were small, especially in years 4 and 5 .

Antiplatelet therapy is an important component of CAD management [18]. Within the antiplatelet agents aspirin is the most important drug in the prevention of arterial thrombosis. This could also be seen in the present analysis. The benefit of the treatment with aspirin was shown in various studies and international guidelines [17, 36]. A meta-analysis showed that low-dose aspirin therapy (50-325 mg/day) is associated with a reduction of cardiovascular events and the risk of all-cause mortality but an important side effect is major bleeding [41]. Overall, $2.1 \%$ of Austrian 
patients were affected by major bleeding during the CLARIFY observation period, which corresponds to results in previous studies [41]. Several factors such as treatment duration, comedications or nonadherence to therapy have been shown to be associated with aspirin resistance [42]. Alternative agents are thienopyridine derivates such as clopidogrel, which act as antagonists of the platelet adenosine diphosphate receptor $\mathrm{P}_{2} \mathrm{Y}_{12}$. The benefit of clopidogrel compared with aspirin was shown in patients with previous myocardial infarction, stroke or peripheral vascular disease [43]. In Austria, thienopyridines were used in approximately $10 \%$ of patients. This is consistent with the recommendations of the European Society of Cardiology (ESC) proposing clopidogrel as second-line treatment, especially for aspirin-intolerant patients with CAD [17].

Revascularization was performed in $9.2 \%$ of patients, but most patients had a history of PCI or CABG. In patients with acute coronary syndromes revascularization reduces cardiovascular death and MI compared with conservative treatment [44, 45]; however, controversy exists over the benefit of revascularization in patients with chronic stable CAD compared with medical management [44, 46], and large studies are underway to settle this issue (ISCHEMIA trial, clinicaltrials.gov, NCT01471522). Results from the COURAGE study implicated that PCI did not reduce risk of death, MI and other cardiovascular events when added to current medical treatment in patients with stable CAD [47]. In contrast, a large meta-analysis resulted in a benefit of revascularization. The positive effects of revascularization are clearly shown in patients with anginal symptoms. In these cases, PCI or CABG more effectively relieve angina, reduce treatment with anti-anginal drugs as well as improve physical resilience and quality of life [48]. In this context, the ESC guidelines recommend revascularization on the basis of the presence of significant coronary artery stenosis, the severity of ischemia and the expected benefit for prognosis [17].

The primary outcome, defined as the composite of cardiovascular death, MI or stroke over 5 years occurred in $7.1 \%$ of patients, less frequently than in the rest of CLARIFY population $(8.7 \%)$. The same could be found for cardiovascular death, all-cause death and hospitalization for heart failure, whereas the frequency of MI (fatal or non-fatal) and stroke (fatal or non-fatal) was very similar. The results are consistent with clinical trials such as COURAGE or CORONOR as well as the Euro Heart Survey which found an estimated annual mortality rate of $1.2-2.4 \%$, an estimated annual incidence of cardiovascular death between $0.6 \%$ and $1.4 \%$ and an estimated annual incidence of non-fatal MI between $0.6 \%$ and $2.7 \%$ [ 47 , $49,50]$

The Austrian CLARIFY cohort was relatively small, especially the patient population with anginal symptoms. Thus, we cannot exclude selection bias. In ad- dition, symptoms and outcomes were based on reporting by the investigator, and not on standardized questionnaires or calibrated tests. Finally, more than $25 \%$ of patients were lost to follow-up. Thus, for a better understanding of the management and outcome of stable CAD in Austria studies with larger numbers of patients are needed.

\section{Conclusion}

The characteristics of Austrian outpatients with stable CAD corresponded to those found in other developed countries and treatments followed the recommendations of the European guidelines. Thus, patients received LLD, aspirin, beta-blockers and ACE inhibitors; however, recommended goals of life style interventions including a heart rate less than $60 \mathrm{bpm}$ and general risk factor management were not achieved by the majority of patients. Heart rate control and life style changes remain unmet needs of cardiovascular care in Austria.

Acknowledgements Open access funding provided by Medical University of Vienna. This study was supported by research grants from Servier, France. Authors are grateful to all CLARIFY investigators. Dr. Karola Wittig, provided editorial assistance in the preparation of the manuscript, tables, and figures and was funded by the sponsor.

Funding This study was supported by research grants from Servier, France (http://www.clarify-registry.com). The study was designed and conducted by the investigators and funded via grants from Servier, including grants to the academic statistical center. The sponsor was sent the manuscript before submission.

\section{Compliance with ethical guidelines}

Conflict of interest I.M. Lang reports receiving consulting fees from AOPOrphan Pharmaceuticals, Actelion, BayerSchering, Astra-Zeneca, Servier, Cordis, Medtronic, GSK, Novartis, Pfizer, and United Therapeutics. In addition to being investigator in trials involving these companies, relationships include research grants and membership of scientific advisory boards. R. Badr-Eslam, N. Greenlaw, R. Young, and P.G. Steg declare that they have no competing interests.

Ethical standards All procedures performed in studies involving human participants were carried in accordance with the ethical standards of the appropriate ethics committee and national law and the Helsinki Declaration from 1964 (in its current revised form). Informed consent was obtained from all participants in the study.

Open Access This article is distributed under the terms of the Creative Commons Attribution 4.0 International License (http://creativecommons.org/licenses/by/4.0/), which permits unrestricted use, distribution, and reproduction in any medium, provided you give appropriate credit to the original author(s) and the source, provide a link to the Creative Commons license, and indicate if changes were made. 


\section{Appendix}

\section{Full list of the CLARIFY investigators}

Austrian CLARIFY investigators: Franz Michael Auhser, Andreas Beinhauer, Gerald Bode, Alexander Dzien, Michael Felbermayer, Michel Feldner-Busztin, Wolfgang Filip, Johannes Föchterle, Ursula Frank, Elisabeth Galehr, Walter Gritsch, Valery Hadjiivanov, Peter Haralambus, Rainer Herrmann, Thomas Honsig, Karl-Heinz Karner, Raimund Kaserbacher, Doris Kerö, Lucas Kleemann, Claus Lavicka, Mahr Andreas, Karl Mayr, Herbert Mayr, Regina Mika, Martin Georg Millauer, Beate Mörz-Proszowski, Ewald Moser, Peter Painsipp, Thomas Perger, Rudolf Raffelsberger, Roland Schwarz, Gabriele Sepp, Günter Steurer, Anton Suntinger, Ursula Teleky, Hildgard Topf, Joachim Toplak, Kurt Walcher, Erich Ziak.

\section{References}

1. WHO. The global burden of disease: 2004 update. 2004. www.who.int/healthinfo/global_burden_disease/2004_ report_update/en/index.html. Accessed: 26. Jul 2016.

2. Wong ND. Epidemiological studies of CHD and the evolution of preventive cardiology. Nat Rev Cardiol. 2014;11:276-89.

3. Mathers CD, Loncar D. Projections of global mortality and burden of disease from 2002 to 2030. PLoS Med. 2006;3:e442.

4. Steg G, on behalf of the BEAUTIFUL Executive Committee, editors. The CLARIFY registry: management of stable coronary artery disease in clinical practice. Brochure for participating doctors. 2009.

5. Leal J, Luengo-Fernández R, Gray A, Petersen S, Rayner M. Economic burden of cardiovascular diseasesin the enlarged European Union. Eur Heart J. 2006;27:1610-9.

6. Steg PG, Glreenlaw N, Tendera M, Tardif JC, Ferrari R, AlZaibag M, Dorian P, Hu D, Shalnova S, Sokn FJ, Ford I, Fox KM, for the CLARIFY Investigators. Prevalence of anginal symptoms and myocardial ischemia and their effect on clinical outcomes in outpatients with stable coronary artery disease. Data from the international observational CLARIFY registry. JAMA Intern Med. 2014;174(10):1651-9.

7. Tunstall-Pedeo H, Kuulasmaa K, Mähönen M, Tolonen H, Ruokokoski E, Amouyel P, for the WHO MONICA (monitoring trends and determinants in cardiovascular disease) Project. Contribution of trends in survival and coronary event rates to changes in coronary heart disease mortality: 10-year results from $37 \mathrm{WHO}$ MONICA project populations. Lancet. 1999;353:1547-57.

8. Fox KM, EURopean trial On reduction of cardiac events with Perindopril in stable coronary Artery disease Investigators. Efficacy of perindopril in reduction of cardiovascular events among patients with stable coronary disease: randomised, double-blind, placebo-controlledmulticentretrial(theEUROPAstudy). Lancet. 2003;362:782-8.

9. Alcocer-Gamba MA, Martinez-Sanchez C, Verdejo-Paris J, Ferrari R, Fox K, Greenlaw N, Steg PG, for the CLARIFY investigators. Heart rate and use of $\beta$-blockers in Mexican stable outpatients with coronary artery disease. Arch Cardiol Mex. 2015;85(4):270-7.
10. Steg PG. Heart rate management in coronary artery disease: the CLARIFY registry. Eur Heart J. 2009;11(Suppl D):D13-D8

11. Erglis A, Mintale I, Latkovskis G, Balode I, Jegere S, Bajare I, Rozenbergs A, Greenlaw N, Ferrari R, Steg PG, for the CLARIFY registry investigators. Management of coronary artery disease patients in Latvia compared with practice in Central-Eastern Europa and globally: analysis of the CLARIFY registry. Medicina (B Aires). 2015;51:240-6.

12. Steg PG, Ferrari R, Ford I, Greenlaw N, Tardif JC, Tendera M, Abergel H, Fox KM, for the CLARIFY investigators. Heart rate and use of beta-blockersin stable outpatients with coronary artery disease. PLOS ONE. 2012;7(5):e36284.

13. R Core Team. R: a language and environment for statistical computing. Vienna: R Foundation for Statistical Computing;2014. http://www.R-project.org/.

14. EUROASPIRE II Study Group. Lifestyle and risk factor management and use of drug therapies in coronary patients from 15 countries. Principal results from EUROASPIRE II euro heart survey programme. Eur Heart J. 2001;22:554-72.

15. Daly CA, Clemes F, Lopez Sendon JL, Tavazzi L, Boersma E, Danchin N, Delahaye F, Gitt A, Julian D, Mulcahy D, Ruzyllo W, Thygesen K, Verheugt F, Fox KM, on behalf of the Euro Heart Survey investigators. The initial management of stable angina in Europe, from the Euro Heart Survey. A description of pharmacological management and revascularization strategies initiated within the first month of presentation to a cardiologist in the Euro Heart Survey of stable angina. Eur Heart J.2005;26:1011-22.

16. Steg PG, Greenlaw N, Tardif JC, Tendera M, Ford I, Kääb S, Abergel H, Fox KM, Ferrari R, on behalf of the CLARIFY registry investigators. Women and men with stable coronary artery disease have similar clinical outcomes: insights from the international prospective CLARIFY registry. Eur Heart J. 2012;33:2831-40.

17. MontalescotG, Sechtem U, Achenbach S, AndreottiF,Arden C, Budaj A, Bugiardini R, Crea F, Cuisset T, Di Mario C, Ferreira JR, Gersh BJ, Gitt AK, Hulot JS, Marx N, Opie LH, Pfisterer M, Prescott E, Ruschitzka F, Sabaté M, Senior R, TaggartDP, van der WallEE, Vrints CJM. 2013 ESC guidelines on the management of stable coronary artery disease. Eur Heart J.2013;34:2949-3003.

18. Pflieger M, Winslow BT, Mills K, Dauber IM. Medical management of stable coronary artery disease. Am Fam Physician. 2011;83:819-26.

19. Simoons ML, Windecker S. Chronic stable coronary artery disease: drugs vs. revascularization. Eur Heart J. 2010;31:530-41.

20. Daly CA, Clemes F, Lopez Sendon JL, Tavazzi L, Boersma E, Danchin N, Delahaye F, Gitt A, Julian D, Mulcahy D, Ruzyllo W, Thygesen K, Verheugt F, Fox KM, on behalf of the Euro Heart Survey investigators. The clinical characteristics and investigations planned in patients with stable angina presenting to cardiologists in Europe: from the Euro Heart Survey of stable angina. Eur HeartJ. 2005;26:996-1010.

21. Erglis A, Mintale I, Latkovskis G, Balode I, Jegere S, Bajare I, Rozenbergs A, Greenlaw N, Ferrari R, Steg PG, for the CLARIFY registry investigators. Management of coronary artery disease patients in Latvia compared with practice in Central-Eastern Europe and globally: analysis of the CLARIFY registry. Medicina (B Aires). 2015;51:240-6.

22. Lerner A, Kannel W. Patterns of coronary heart disease morbidity and mortality in the sexes: a 26 year follow-up of the Framingham population. Am Heart J. 1985;111:383-90.

23. Kotseva K, Wood D, De Backer G, De Bacquer D, Pyöräläc K, Keil U, EUROASPIRE Study Group. EUROASPIRE III: a surveyon thelifestyle, riskfactors and use of cardioprotec- 
tive drug therapies in coronary patients from 22 European countries. Eur J Prev Cardiol. 2009;16:121-37.

24. Van Berkel TFM, Boersma H, Roos-Hesselink JW, Erdman RAM, Simoons ML. Impact of smoking cessation and smoking interventions in patients with coronary heart disease. Eur Heart J. 1999;20:1773-82.

25. IARC. Reversal of risk after quitting smoking. IARC Handbooks of Cancer Prevention, Tobacco control, vol 11. Lyon, Geneva: IARC, World Health Organization; 2007.

26. Löwel H, Koenig W, Engel S, Hormann A, Keil U. The impact of diabetes mellitus on survival after myocardial infarction: can it be modified by drug treatment? Results of a population-based myocardial infarction register followup study. Diabetologia. 2000;43:218-26.

27. Steg PG, Ducrocq G. Future of the prevention and treatment of coronary artery disease. Circ J. 2016;80:1067-72.

28. Cholesterol Treatment Trialists' (CTT) Collaboration. Efficacy and safety of more intensive lowering of LDL cholesterol: a meta-analysis of data from 170,000 participants in 26 randomised trials. Lancet. 2010;376:1670-81.

29. Nicholls SJ, Tuzcu M, Sipahi I, Grasso AW, Schoenhagen P, Hu T, Wolski K, Crowe T, Desai MY, Hazen SL, Kapadia SR, Nissen SE. Statins, high-density lipoprotein cholesterol, and regression of coronary atherosclerosis. JAMA. 2007;297:499-508.

30. Flack LM, Neaton J, Grimm R, Shih J, Cutler J, Ensrud $\mathrm{K}$, MacMahon S. Blood pressure and mortality among men with prior myocardial infarction. Circulation. 1995;92:2437-45.

31. SPRINT Research Group, Wright JTJr., Williamson JD, Whelton PK, etal. A randomized trial of intensive versus standard blood-pressure control. NEngl J Med. 2015;373:2103-16.

32. Vidal-Tetiot E, Ford I, Greenlaw N, Ferrari R, Fox KM, Tardif JC, Tendera M, Tavazzi L, BhattDL, Steg PG, for the CLARIFY investigators. Cardiovascular event rates and mortality according to achieved systolic and diastolic blood pressure in patients with stable coronary artery disease: an international cohort study. Lancet. 2016;388(10056):2142-52. doi:10.1016/s0140-6736(16)31326-5.

33. FrakerTD, FihnSD, writing on behalf of the 2002 chronic stable angina writing committee. 2007 chronic angina focused update of the ACC/AHA 2002 guidelines for the management of patients with chronic stable angina: a report of the American College of Cardiology/American Heart Association Task Force on Practice Guidelines Writing Group to develop the focused update of the 2002 guidelines for the management of patients with chronic stable angina. Circulation. 2007;116:2762-72. published correction appears in Circulation 2007;116:e558.

34. Heidenreich PA, McDonald KM, Hastie T, Fadel B, Hagan V, Lee BK, Hlatky MA. Meta-analysis of trials comparing beta-blockers, calcium antagonists, and nitrates for stable angina. JAMA. 1999;281:1927-36.

35. FoxK, Garcia MAA, Ardissino D, Buszman P, Camici PG, Crea F, Daly C, De Backer G, Hjemdahl P, Lopez-Sendon J, Marco J, Morais J, Pepper J, Sechtem U, Simoons M, Thygesen K. Guidelines on the management of stable angina pectoris: executive summary. Eur HeartJ. 2006;27:1341-81.

36. Tardif JC, Ford I, Tendera M, Bourassa MG, Fox K, for the INITIATIVE investigators. Efficacy of ivabradine, a new selective If inhibitor, compared with atenolol in patients with chronic stable angina. Eur Heart J. 2005;26:2529-36.

37. Tardif JC, Ponikowski P, Kahan T, for the ASSOCIATE study investigators. Efficacy of the If current inhibitor ivabradine in patients with chronic stable angina receiving betablocker therapy: a 4 month, randomized, placebo-controlled trial. Eur Heart J. 2009;30:540-8.

38. Amosova E, Andrejev E, Zaderey I, Rudenko U, Ceconi C, Ferrari R. Efficacy of ivabradine in combination with betablocker versus uptitration of beta-blocker in patients with stable angina. Cardiovasc Drugs Ther. 2011;25:531-7.

39. Werdan K, Ebelt H, Nuding S, Höpfner F, Hack G, MüllerWerdan U. Ivabradine in combination with beta-blocker improves symptoms and quality of life in patients with stable angina pectoris: results from the ADDITIONS study. Clin Res Cardiol. 2012;101:365-73.

40. Werdan K, Ebelt H, Nuding S, Höpfner F, Stöckl G, MüllerWerdan U. Ivabradine in combination with beta-blockers in patients with chronic stable angina after percutaneous coronary intervention. AdvTher. 2015;32:120-37.

41. Berger JS, Brown DL, Becker RC. Low-dose aspirin in patients with stable cardiovascular disease: a meta-analysis. AmJ Med. 2008;121:43-9.

42. Mason PJ, Jacobs AK, Freedman JE. Aspirin resistance and atherothrombotic disease. J Am Coll Cardiol. 2005;46:986-93.

43. CAPRIE Steering Committee. A randomised, blinded trial of clopidogrel versus aspirin in patients at risk of ischaemic events (CAPRIE). Lancet. 1996;348:1329-39.

44. Simoons ML, Windecker S. Chronic stable coronary artery disease: drugs vs. revascularization. Eur Heart J. 2010:31:530-41.

45. Bassand JP, Hamm CW, Ardissino D, Boersma E, Budaj A, Fernandez-AvilesF, FoxKA, HasdaiD, OhmanEM, Wallentin L, Wijns W. Guidelines for the diagnosis and treatment of non-ST-segment elevation acute coronary syndromes. Eur Heart J.2007;28:1598-660.

46. Hochmann JS, Steg PG. Does preventive PCI work? N Engl J Med. 2007;356:1572-4.

47. Boden WE, O'Rourke RA, Teo KK, Hartigan PM, Maron DJ, Kostuk WJ, Knudtson M, Dada M, Casperson P, Harris CL, Chaitman BR, Shaw L, Gosselin G, Nawaz S, Title LM, Gau G, Blaustein AS, Booth DC, Bates ER, Spertus JA, Berman DS, Mancini GBJ, WeintraubWS, for the COURAGE Trial Research Group. Optimal medical therapy with or without PCI for stable coronary disease. N Engl J Med. 2007;356:1503-16.

48. Mukherjee D, Moliterno DJ. Effectiveness of PCI for nonacute coronary artery disease. Lancet. 2009;373:870-2.

49. Bauters C, Deneve M, Tricot O, Meurice T, Lamblin N, on behalf of the CORONOR investigators. Prognosis of patients with stable coronary artery disease (from the CORONOR study). Am J Cardiol. 2014;113:1142-5.

50. Daly CA, DeStavola B, Lopez-Sendon JL, Tavazzi L, Boersma E, Clemens F, Danchin N, Delahaye F, Gitt A, Julian D, Mulcahy D, Ruzyllo W, Thygesen K, Verheugt F, Fox KM, on behalf of the Euro Heart Survey investigators. Predicting prognosis in stable angina - results from the Euro Heart Survey of stable angina: prospective observational study. BMJ. 2006;332:262-7. 